\title{
Pengelompokkan Karakteristik Konsumen PT Sumber Pengiriman Majujaya Pada Departemen Custom Clearance
}

\author{
Tamadara Hilman, Ni Made Asri Miangi \\ ${ }_{1}$ D4 Logistik Bisnis, Politeknik Pos Indonesia \\ email: tamadara@poltekpos.ac.id \\ ${ }_{2}$ D4 Logistik Bisnis, Politeknik Pos Indonesia \\ email: asrimiangi6@gmail.com
}

\begin{abstract}
Abstrak
Penanganan konsumen dalam pembuatan draft PIB di Departemen Custom Clearance (CC) PT SPM belum mencapai KPI yang ditargetkan. Sistem pengkategorian konsumen belum ditentukan perusahaan sehingga karyawan mengerjakan draft PIB tanpa melihat konsumen yang seharusnya menjadi prioritas. Konsumen prioritas yang terabaikan menyebabkan adanya pembatalan penggunaan jasa kepabeanan. Berdasarakan KPI dari Departemen CC, draft PIB seharusnya diselesaikan dalam waktu 1 sampai 3 hari. Pada kenyataannya waktu rata-rata penerbitan draft PIB yaitu selama 4,11 hari. Untuk mencapai KPI yang ditargetkan, salah satu cara yang dapat dilakukan adalah dengan mengkategorikan konsumen sesuai dengan variabel karakteristik yang serupa. Metode yang digunakan dalam penelitian ini adalah clustering k-means dan analisis diskriminan. Variabel yang digunakan yaitu waktu rata-rata penerbitan draft PIB, frekuensi pengiriman, biaya total, dan rata-rata ruang kargo. Penelitian ini menghasilkan lima kelompok konsumen dengan tingkat kepentingan berbeda, berdasarkan hasil analisis dikriminan dengan faktor pembeda utama yaitu biaya total. Kelima kelompok tersebut adalah Cluster 5 (konsumen yang sangat memberikan benefit bagi Departemen CC); Cluster 2 (konsumen yang memberikan benefit bagi Departemen CC); Cluster 1 (konsumen yang cukup memberikan benefit bagi Departemen CC); Cluster 3 (konsumen yang kurang memberikan benefit bagi Departemen CC); dan Cluster 4 (konsumen yang sangat kurang memberikan benefit bagi Departemen $C C)$.
\end{abstract}

Kata Kunci: Konsumen, Pelayanan, Cluster K-means, Analisis Diskriminan

\section{PENDAHULUAN}

PT Sumber Pengiriman Majujaya (SPM) merupakan perusahaan freight forwarding yang memiliki gudang Tempat Penimbunan Sementara (TPS). TPS tersebut berada dibawah pengawasan Direktorat Bea dan Cukai sehingga PT SPM memiliki departemen khusus yang melayani proses jasa kepabeanan yaitu Departemen Custome Clearance (CC). Salah satu dokumen yang penting dalam pengeluaran barang yaitu draft PIB. Namun, sistem pengkategorian konsumen belum diterapkan di perusahaan sehingga pengerjaan draft PIB dilakukan tanpa melihat kepentingan konsumen. Hal tersebut menyebabkan konsumen prioritas terabaikan dan terjadi pembatalan penggunaan jasa kepabeanan. Waktu rata-rata penerbitan draft PIB yaitu selama 4,11 hari, sedang target KPI dalam pembuatan PIB adalah 1-3 hari seperti yang tercantum pada Tabel 1 .

\section{Tabel 1 Konsumen Departemen CC (Februari-Juli} 2019)

\begin{tabular}{|c|l|c|c|}
\hline No & \multicolumn{1}{|c|}{ Nama Perusahaan } & $\begin{array}{c}\text { Rata- rata Issuing } \\
\text { Draft PIB (Hari) }\end{array}$ & $\begin{array}{c}\text { Frekuensi } \\
\text { Pengiriman }\end{array}$ \\
\hline 1 & PT MEDTRONIC INDONESIA & 2,5 & 398 \\
\hline 2 & PT ABB SAKTI INDUSTRI & 8,3 & 379 \\
\hline 3 & PT ENDRESS + HAUSER INDONESIA & 6 & 232 \\
\hline 4 & PT GE OPERATIONS INDONESIA & 3,5 & 187 \\
\hline 5 & PT PALL FILTRATION INDONESIA & 4,4 & 183 \\
\hline 6 & PT HALLIBURTON INDONESIA & 3,6 & 150 \\
\hline 7 & PT BAKER HUGHES INDONESIA & 3,7 & 115 \\
\hline 8 & PT HALLIBURTON DRILLING SYSTEMS INDONESIA & 4 & 114 \\
\hline 9 & PT DANFOSS INDONESIA & 8,5 & 84 \\
\hline 10 & PT GARUDA MATARAM MOTOR & 4,5 & 84 \\
\hline 11 & Perusahaan Lainnya (252 Perusahaan) & $1.027,4$ & 1.136 \\
\hline & & 4,11 & 3.062 \\
\hline
\end{tabular}

Sumber: PT SPM, 2019

Untuk meneliti perusahaan forwarder, terdapat empat dimensi faktor yang digunakan yaitu convenience of 
operation process, aggregated service, excellent transit handling dan rationalization of freight rate (Lin, 2011). Sedangkan metode untuk mengelompokkan konsumen dan menganalisis perilaku adalah clustering. Teknik clustering dapat membantu perusahaan untuk mengelompokkan konsumen menjadi satu cluster yang sama dengan karakteristik cara, tujuan, dan perilaku yang serupa (Ghzanfari, 2010). Penelitian mengenai pengelompokkan konsumen sudah pernah dilakukan pada perusahaan freight forwarding. Tujuan penelitian yang dilakukan adalah untuk mengetahui faktor penyebab perbedaan pelayanan yang diberikan kepada setiap pelanggan, kemudian mengelompokkan pelanggan berdasarkan pelayanan yang diberikan dan mengetahui perbedaan yang ada antara kelompok pelanggan. Metode yang digunakan adalah metode analisis faktor, metode analisis cluster dan metode analisis diskriminan (Sharah, 2015).

Untuk memberi solusi bagi PT SPM, diperlukan suatu metode pengelompokkan konsumen sesuai dengan karateristik serupa. Tujuannya untuk mengetahui variabel karakteristik konsumen PT SPM sehingga konsumen dapat bertahan (loyal) untuk jangka panjang dan mengetahui faktor yang membedakan antar anggota pada setiap cluster konsumen PT SPM. Penelitian ini diharapkan dapat menjadi referensi bagi perusahaan dalam memberikan pelayanan kepada cluster konsumen yang diprioritaskan.

\section{METODE PENELITIAN}

Pengelompokkan konsumen Departemen CC PT SPM perlu dilakukan agar perusahaan dapat memberi layanan bagi konsumen prioritas sehingga tidak terjadi lagi pembatalan penggunaan jasa kepabeanan. Metode penelitian yang digunakan adalah clustering k-means dan analisis diskriminan.

\section{Metode yang Digunakan}

Metode clustering k-means yang digunakan berfungsi untuk membentuk suatu cluster dengan karakteristik yang serupa. Proses clustering dengan algoritma K-Means adalah sebagai berikut (Suyonto, 2019):

1. Tentukan banyaknya cluster yang diinginkan

2. Alokasikan data sesuai dengan jumlah cluster yang telah ditentukan

3. Tentukan nilai centroid pada tiap-tiap cluster

4. Hitung jarak terdekat dengan menggunakan rumus Euclidean

5. Tampilkan hasil berdasarkan jarak terendah dari hasil perhitungan rumus Euclidean
6. Jika belum didapatkan hasil yang sesuai, iterasi kembali dilanjutkan dengan menentukan lagi nilai centroid pada tiap-tiap cluster. Iterasi akan dihentikan jika hasil clustering sudah sama dengan iterasi sebelumnya

Sedangkan analisis diskriminan yang digunakan berfungsi untuk menguatkan hasil output dari analisis cluster dilakukan dengan mencari akar persamaan yang membedakan antara karakteristik antara anggota dalam sebuah cluster. Analisis diskriminan terdiri dari lima tahap yaitu (Simamora dalam Malhotra, 2005):

1. Merumuskan masalah

2. Mengestimasi koefisien fungsi diskriminan

3. Memastikan signifikansi determinan

4. Menginterpretasi hasil

5. Menguji signifikansi analisis diskriminan

\section{Operasional Variabel}

Variabel yang digunakan untuk menentukan karakteristik dari konsumen Departemen CC sebagai berikut:

Tabel 2 Operasional Variabel

\begin{tabular}{|l|l|}
\hline \multicolumn{1}{|c|}{ Variabel } & \multicolumn{1}{c|}{ Sub Variabel } \\
\hline Convenience of operation process & Ketersediaan ruang kargo CC Departemen \\
\hline Aggregated service & Kecepatan dalam menerbitkan draft PIB oleh CC Departemen \\
\hline Excellent transit handling & Frekuensi pengiriman yang dilakukan CC Departemen \\
\hline Rationalization of freight rate & Total biaya setiap dokumen CC Departemen \\
\hline
\end{tabular}

Sumber: Pengolahan Data, 2019

\section{Teknik Pengumpulan Data}

Teknik yang digunakan untuk mengumpukan data dalam penelitian ini dengan cara studi pustaka dan observasi. Observasi merupakan pengamatan tentang keadaan yang ada di lapangan.

\section{Kerangka Pemikiran}

Dalam kasus PT SPM, penanganan konsumen dalam pembuatan draft PIB merupakan salah satu aktivitas utama. Perlu dilakukan pengelompokkan konsumen dengan menggunakan metode analisis cluster dan analisis diskriminan. Atribut yang digunakan untuk menentukan karakteristik konsumen didapat berdasarkan empat dimensi kualitas pelayanan pada perusahaan jasa freight forwarding yaitu convenience of operation process, aggregated service, excellent transit handling dan rationalization of freight rate. Berikut merupakan kerangka pemikiran dalam penelitian ini: 


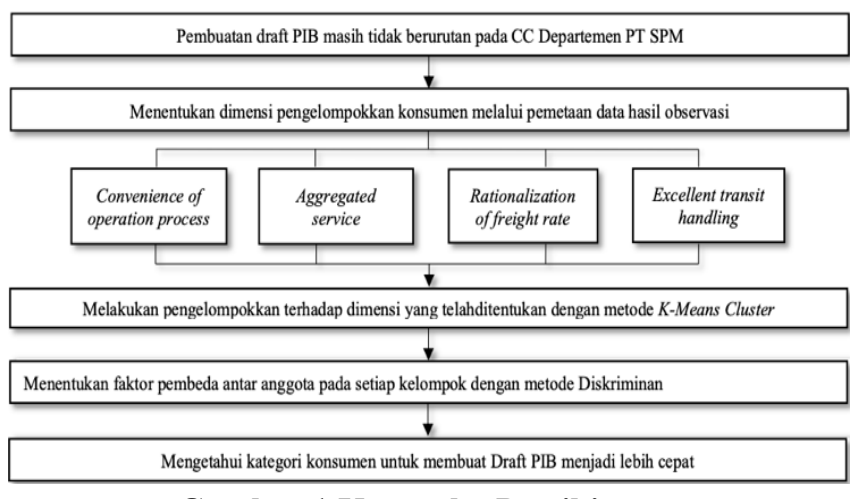

Gambar 1 Kerangka Pemikiran

\section{HASIL DAN PEMBAHASAN}

\section{Metode Cluster K-Means}

a. Penentuan jumlah Cluster

Jumlah data dalam penelitian ini yaitu 262 perusahaan dan empat sub atribut yang kemudian dilakukan pengolahan data dengan aplikasi SPSS. Hasil pengolahan data dengan metode algoritma Ward melalui aplikasi SPSS yaitu tabel Agglomeration Schedule yang dapat dilihat pada tabel 3 .

Tabel 3 Hasil Agglomeration Schedule

\begin{tabular}{|c|c|c|c|}
\hline \multicolumn{4}{|c|}{ Agglomeration Schedule } \\
\hline Stage & Cluster & Coefficients & $\begin{array}{c}\text { Coefficients } \\
\text { Difference }\end{array}$ \\
\hline 254 & 8 & 79,025 & 15,077 \\
\hline 255 & 7 & 97,534 & 18,509 \\
\hline 256 & 6 & 124,042 & 26,508 \\
\hline $\mathbf{2 5 7}$ & $\mathbf{5}$ & $\mathbf{1 6 6 , 0 5 1}$ & 42,009 \\
\hline 258 & 4 & 237,793 & $\mathbf{7 1 , 7 4 2}$ \\
\hline 259 & 3 & 357,246 & 119,453 \\
\hline 260 & 2 & 517,516 & 160,27 \\
\hline
\end{tabular}

Sumber: Pengolahan Data SPSS, 2019

Jumlah cluster yang optimal didapatkan dengan melihat loncatan nilai koefisien terbesar pertama. Pada Tabel 2 terlihat bahwa besar loncatan koefisien antara stage 257 dengan 258 adalah sebesar 71,742 dan merupakan loncatan terbesar pertama diantara stage lainnya. Maka jumlah cluster optimal yang digunakan dalam pengolahan data metode clustering algoritma K-Means adalah lima cluster.

b. Proses metode clustering algoritma K-Means Berdasarkan 262 data konsumen yang diteliti maka proses iterasi dilakukan dengan menggunakan aplikasi SPSS. Proses iterasi untuk mendapatkan cluster secara optimal dilakukan secara tiga kali.
Tabel 4 Final Cluster Centers

\begin{tabular}{|l|r|r|r|r|r|}
\hline \multirow{2}{*}{} & \multicolumn{5}{|c|}{ Cluster } \\
\cline { 2 - 6 } & \multicolumn{1}{|c|}{1} & 2 & 3 & \multicolumn{1}{c|}{4} & \multicolumn{1}{c|}{5} \\
\hline Zscore(Average,of,Issuing,PIB) & $-1,19204$ & 3,68523 &, 81213 &,- 03072 &, 40569 \\
\hline Zscore(Frekuensi,Pengiriman) & 8,98775 & 8,54571 & 3,14812 &,- 15971 & 3,98568 \\
\hline Zscore(Biaya,total) & 4,47087 & 5,83065 & 1,17275 &,- 12152 & 13,40685 \\
\hline Zscore(Average,of,cargo,space) & 10,34424 & 6,99957 & 2,98358 &,- 15783 & 4,68639 \\
\hline
\end{tabular}

Sumber: Pengolahan Data SPSS, 2019

Hasil final cluster pada tabel 4 kemudian diolah dengan data $z$-score untuk membantu memberikan keputusan pada Departemen CC dalam mengelompokkan konsumennya masuk kedalam 1, 2, 3,4 atau 5 yang hasilnya dapat dilihat pada tabel 5 berikut.

Tabel 5 Cuplikan Hasil Clustering

\begin{tabular}{|c|c|c|}
\hline SYM DATA & Cluster & Distance \\
\hline $\mathrm{X} 1$ & 1 & 0 \\
\hline $\mathrm{X} 2$ & 2 & 0 \\
\hline $\mathrm{X} 3$ & 3 & 2,47239 \\
\hline $\mathrm{X} 4$ & 3 & 2,21032 \\
\hline $\mathrm{X} 5$ & 5 & 0 \\
\hline $\mathrm{X} 6$ & 3 & 2,7544 \\
\hline $\mathrm{X} 7$ & 3 & 2,00298 \\
\hline $\mathrm{X} 10$ & 4 & 2,15793 \\
\hline $\mathrm{X} 12$ & 4 & 2,25826 \\
\hline
\end{tabular}

Sumber: Hasil Pengolahan Data SPSS, 2019

Berdasarkan tabel 5 maka anggota yang terbentuk pada masing-masing cluster dapat dilihat pada tabel 6 berikut.

Tabel 6 Number of Cases in each Cluster

\begin{tabular}{|l|l|r|}
\hline \multirow{4}{*}{ Cluster } & 1 & 1,000 \\
\cline { 2 - 3 } & 2 & 1,000 \\
\cline { 2 - 3 } & 3 & 6,000 \\
\cline { 2 - 3 } & 4 & 253,000 \\
\cline { 2 - 3 } & 5 & 1,000 \\
\hline Valid & 262,000 \\
\hline Missing &, 000 \\
\hline
\end{tabular}

Sumber: Hasil Pengolahan Data SPSS, 2019

\section{Analisis Diskriminan}

Berdasarkan data hasil pengelompokkan dari analisis cluster, kemudian dilakukan analisis diskriminan. Hasil dari analisis diskriminan didapat bahwa yang menjadi faktor pembeda utama adalah biaya total dengan memiliki korelasi cukup erat yang ditampilkan pada tabel 7 berikut. 
Tabel 7 Structure Matrix

\begin{tabular}{|c|c|c|c|}
\hline \multicolumn{4}{|c|}{ Structure Matrix } \\
\hline & \multicolumn{3}{|c|}{ Function } \\
\hline & 1 & 2 & 3 \\
\hline Biaya,total &, $886^{*}$ &,- 413 & 209 \\
\hline Frek,Pengi & ,591 & $693^{*}$ & ,414 \\
\hline Average,of,cargo,space & ,631 & $688^{+}$ &,- 358 \\
\hline Average,of,Issuing,PIB ${ }^{b}$ &,- 084 &,- 011 &, $149^{*}$ \\
\hline \multicolumn{4}{|c|}{$\begin{array}{l}\text { Pooled within-groups correlations between discriminating variables and standardized } \\
\text { canonical discriminant functions } \\
\text { Variables ordered by absolute size of correlation within function. }\end{array}$} \\
\hline \multicolumn{4}{|c|}{ *. Largest absolute correlation between each variable and any discriminant function } \\
\hline$b$, This variable not used & ysis, & & \\
\hline
\end{tabular}

\section{Sumber: Hasil Pengolahan Data SPSS, 2019}

Serta diperoleh informasi bahwa semua obyek pengelompokkan sesuai dengan data hasil dari analisis cluster. Hal ini diperkuat dengan hasil output tabel 8 sebagai berikut.

Tabel 8 Classification Results ${ }^{a, \mathrm{c}}$

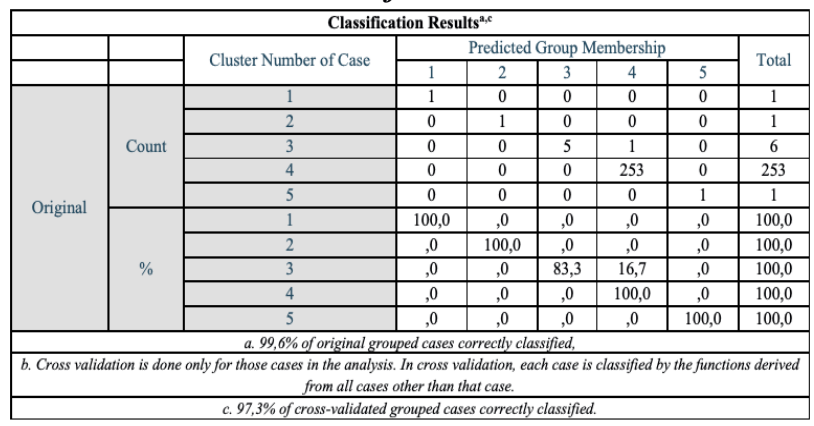

Sumber: Hasil Pengolahan Data SPSS, 2019

Pada tabel 8 tampak bahwa angka ketepatan prediksi sebesar $99,6 \%$.

\section{Pembahasan}

Setelah melakukan pengolahan data dengan mengunakan metode analisis clustering $k$-means berdasarkan sub atribut yang digunakan maka dapat diketahui karakteristik konsumen pada masing-masing cluster yang hasilnya dapat dilihat pada tabel 8 berikut.

\section{Tabel 8 Analisis Karakterisik Konsumen Departemen Custom Clearance}

\begin{tabular}{|c|c|}
\hline \multicolumn{2}{|c|}{$\begin{array}{l}\text { Cluster } \mathbf{I} \\
\text { Kelompok konsumen yang cukup memberikan benefit } \\
\text { bagi Departemen CCdan sangat sering menggunakan } \\
\text { produk Departemen CC }\end{array}$} \\
\hline & $\begin{array}{l}\text { Waktu yang diperlukan dalam menerbitkan PIB } \\
\text { yaitu 2,5 hari } \\
\text { Frekuensi pengiriman sekitar } 398 \text { kali } \\
\text { Jumlah biaya yang dikeluarkan konsumen } \\
\text { sekitar Rp 22.048.138.378,722 }\end{array}$ \\
\hline
\end{tabular}

- $\quad$ Ruang kargo yang digunakan konsumen yaitu $684.286,851 \mathrm{~cm}^{3}$

\section{Cluster 2}

Konsumen yang memberikan benefit bagi Departemen CCdan sering menggunakan produk Departemen CC

- Waktu yang diperlukan dalam menerbitkan PIB yaitu 8,3 hari

- $\quad$ Frekuensi pengiriman sekitar 379 kali

- Jumlah biaya yang dikeluarkan konsumen sekitar Rp 28.527.032.102,319

- $\quad$ Ruang kargo yang digunakan konsumen yaitu $467.706,236 \mathrm{~cm}^{3}$

\section{Cluster 3}

Konsumen yang kurang memberikan benefit bagi Departemen CC dan jarang menggunakan produk Departemen CC

- Waktu yang diperlukan dalam menerbitkan PIB yaitu 4.8 hari

- $\quad$ Frekuensi pengiriman sekitar 147 kali

- Jumlah biaya yang dikeluarkan konsumen sekitar Rp 6.333.707.391,599

- $\quad$ Ruang kargo yang digunakan konsumen yaitu $207.654,994 \mathrm{~cm}^{3}$

\section{Cluster 4}

Konsumen yang sangat kurang memberikan benefit bagi Departemen CC dan sangat jarang menggunakan produk Departemen CC

- Waktu yang diperlukan dalam menerbitkan PIB yaitu 3,5 hari

- $\quad$ Frekuensi pengiriman sekitar 5 kali

- Jumlah biaya yang dikeluarkan konsumen sekitar Rp 166.946.754,113

- $\quad$ Ruang kargo yang digunakan konsumen yaitu $4.236,268 \mathrm{~cm}^{3}$

\section{Cluster 5}

Konsumen yang sangat memberikan benefit bagi

Departemen CC dan cukup sering menggunakan produk Departemen CC

- Waktu yang diperlukan dalam menerbitkan PIB yaitu 4.4 hari

- $\quad$ Frekuensi pengiriman sekitar 183 kali

- Jumlah biaya yang dikeluarkan konsumen sekitar Rp 64.625.073.424,237

- $\quad$ Ruang kargo yang digunakan konsumen yaitu $317.918,679 \mathrm{~cm}^{3}$

\section{Sumber: Hasil Pengolahan Data, 2019}

Berdasarkan hasil analisis diskriminan, didapatkan bahwa faktor biaya total yang menjadi pembeda utama antara setiap cluster sehingga urutan tingkat kepentingan konsumen berdasarkan tabel 9 diurutkan sebagai berikut beserta perusahaannya. 
Tabel 9 Anggota Setiap Cluster Berdasarkan Urutan Faktor Biaya Total

\begin{tabular}{|c|c|c|}
\hline Urutan & Cluster & Nama Perusahaan Proritas \\
\hline Ke-1 & Cluster 5 & PT Pall Filtration Indonesia \\
\hline $\mathrm{Ke}-2$ & Cluster 2 & PT ABB Sakti Industri \\
\hline $\mathrm{Ke}-3$ & Cluster 1 & PT Medtronic Indonesia \\
\hline $\mathrm{Ke}-4$ & Cluster 3 & $\begin{array}{l}\text { PT Endress + Hauser } \\
\text { Indonesia, PT GE Operations } \\
\text { Indonesia, PT Halliburton } \\
\text { Indonesia, PT Baker Hughes } \\
\text { Indonesia, PT Halliburton } \\
\text { Drilling Systems Indonesia, } \\
\text { dan PT Danfoss Indonesia }\end{array}$ \\
\hline Ke-5 & Cluster 4 & $\begin{array}{l}\text { PT Garuda Mataram Motor, } \\
\text { PT Halliburton Logging } \\
\text { Services Indonesia, PT Baroid } \\
\text { Indonesia, PT Sandvik } \\
\text { Indonesia, PT Alibaba Cloud } \\
\text { Indonesia dan } 248 \text { perusahaan } \\
\text { lainnya. }\end{array}$ \\
\hline
\end{tabular}

Sumber: Hasil Pengolahan Data, 2019

Serta berdasarkan uraian hasil output SPSS pada analisis diskriminan mengenai Classification Results dapat disimpulkan bahwa fungsi diskriminan yang terbebentuk layak untuk mengklasifikasikan obyek-obyek yang diamati dan dapat memperkuat hasil output analisis cluster bahwa data serta semua kelompok yang terbentuk valid.

\section{KESIMPULAN}

Beberapa kesimpulan yang dapat diambil dari penelitian ini diantaranya adalah sebagai berikut:

- Variabel karakteristik atau sub atribut konsumen yang ada pada perusahaan PT SPM adalah:

1) Rata-rata menerbitkan draft PIB

2) Frekuensi pengiriman

3) Biaya total

4) Rata-rata ruang kargo

- Hasil analisis cluster menghasilkan 5 kelompok konsumen dengan tingkat kepentingan sebagai berikut.

1) Cluster 5, Konsumen yang sangat memberikan benefit bagi CC Departemen dan cukup sering menggunakan produk CC Departemen. Jumlah anggotanya yaitu 1 konsumen.

2) Cluster 2, Konsumen yang memberikan benefit bagi CC Departemen dan sering menggunakan produk CC Departemen. Jumlah anggotanya yaitu 1 konsumen.

3) Cluster 1, Konsumen yang kurang memberikan benefit bagi CC Departemen dan jarang menggunakan produk CC Departemen. Jumlah anggotanya yaitu 1 konsumen.

4) Cluster 3, Konsumen yang sangat kurang memberikan benefit bagi CC Departemen dan sangat jarang menggunakan produk $\mathrm{CC}$ Departemen. Jumlah anggotanya yaitu 6 konsumen.

5) Cluster 4, Konsumen yang sangat kurang memberikan benefit bagi CC Departemen dan sangat jarang menggunakan produk $\mathrm{CC}$ Departemen. Jumlah anggotanya yaitu 253 konsumen.

- Faktor yang membedakan antar anggota pada setiap cluster konsumen CC Departemen PT SPM adalah biaya total.

\section{Saran}

Berdasarkan keimpulan yang telah didapatkan maka saransaran yang dapat diberikan sebagai berikut.

- PT SPM hendaknya memahami identitas atau karakteristik dari konsumen yang akan dilayani guna menjaga jalinan kerjasama agar konsumen dapat bertahan dalam jangka waktu yang lama.

- Mengoptimalkan program Key Performance Indicator agar kecepatan dalam proses bisnis yang dijalani tetap sesuai dengan standar yang telah ditetapkan.

\section{REFERENSI}

\section{Jurnal:}

A. Parvatiyar dan J. N. Sheth. 2001. Customer relationship management: Emerging practice, process and discipline. Journal of Economic and Social Research. 3(2):1-34.

Agusta, Yudhi. 2007. K-Means penerapan permasalahan dan metode terkait. Jurnal Sistem dan Informatika. Vol 3 .

Angelova, Biljana dan Zekiri, Jusuf. 2011. Measuring Customer Satisfaction with Service Quality Using American Customer Satisfaction Model (ACSI Model). International Journal of Academic Research in Business and Social Sciences. 1. 3. 
C. Rygielski, J. Wang dan D. Yen. 2002. Data Mining Techniques For Customer Relationship Management. Technology in Society.24 (4):483-502

D. A. Kandeil, A. A. Saad dan S. M. 2014. Youssef. A twophase clustering analysis for B2B customer segmentation. International Conference on Intelligent Networking and Collaborative Systems. Salerno. pp. 221-228.

D. Liu dan Y. Shih. 2005. Integrating AHP and Data Mining for Product Recommendation based on Customer Lifetime Value. Information \& Management. 42(3):387-400.

J. Lee dan S. Park. 2005. Intelligent Profitable Customers Segmentation System Based On Business Intelligence Tools. Expert Systems with Applications. 29(1):145152.

J. Qian dan C. Gao. 2011. The application of data mining in CRM", in 2nd International Conference on Artificial Intelligence. Management Science and Electronic Commerce (AIMSEC). Deng Leng, pp. 5202-5206.

Larose, Daniel T. 2005. Discovering Knowledge In Data: An Introduction to Data mining. New Jersey: John Willey \& Sons. Inc

Lin, Wen-Cheng dan Liang, Gin-Shuh. 2011. Applying Fuzzy ZOT to Explore the Customer Service Quality to the Ocean Freight Forwarder Industry in Emerging Taiwan Market. Research Journal of Bussiness Management. 5(2):77- 88

Parasuraman, V.A. Zeithaml, L. L. Berry. 1990. Balancing Customer Perceptions and Expectations.

Tripathi, Shreya, Aditya Bhardwaj dan Poovammal E. 2018. Approaches to Clustering in Customer Segmentation. International Journal of Engineering \& Technology. 7 (3.12): 802-807.

V. Zeithaml, R. Rust dan K. Lemon. 2001. The customer pyramid: Creating and serving profitable customers. California Management Review. 43(4): 118-142.

\section{Textbook:}

Assauri, Sofyan. 2004. Manajemen Produksi dan Operasi. Edisi revisi. Jakarta: Lembaga Penerbit FE UI.
C. H. Lovelock, \& L. K. Wright. 2005. Manajemen Pemasaran Jasa. Alih Bahasa. Jakarta: Indeks.

Danang, Sunyoto. 2013. Metodologi Penelitian Akuntansi. Bandung: PT Refika Aditama Anggota Ikapi.

Fandy Tjiptono. 2005. Pemasaran Jasa. Malang: Bayumedia.

Handoko, T. Hani. 1995 Dasar-dasar Manajemen Produksi dan Operasi. Edisi pertama. Yogyakarta: BP-FE.

Heizer, J. \& Render, B. 2005. Operation Management. 7ed prentice. New Jersey: Pearson.

Kotler, Philip. 2005. Manajemen Pemasaran. Jilid Satu Dan Dua. Jakarta: PT Prenhallindo.

Simamora Bilson. 2005. Analisi Multivariat Pemasaran. Jakarta: Gramedia.

Suyanto. 2019. Data Mining untuk Klasifikasi dan Klasterisasi Data. Bandung: Informatika Bandung.

\section{Disertation:}

Sharah, Siti. 2015. Pengelompokkan Custumer berdasarkan Pelayanan yang Diberikan pada Divisi Ekspor PTU KN Sigma Trans. Skripsi tidak diterbitkan. Bandung: Politeknik Pos Indonesia. 